\title{
Relationship between markers of cardiovascular prognosis and mortality at one year in an outpatient population with heart failure
}

\author{
Jimmy Duc* \\ Hopital de Gonesse, 2 bvd 19 mars 1962, 9550 Gonesse, France
}

\begin{abstract}
Objective: This cross-sectional study investigated the difference in association between cardiovascular prognostic markers and one-year mortality in a population with heart failure and followed outpatient.

Method: The data were collected in the medical files of the patients followed in therapeutic unit of heart failure of the hospital of Gonesse in the northeastern region of Paris. The associative method chosen between markers and mortality was the Odd Ratio. The markers most strongly associated with mortality were adjusted to the other co-variables retained.
\end{abstract}

Results: Pro BNP association with mortality emerged predominant. Then were age and clearance as variables strongly associated with mortality. The Pro BNP adjustment to clearance suggested a strong positive interaction between these two variables.

Conclusion: These interesting results were obtained on a small sample in cross-sectional analysis, it would be interesting to compare them to a prospective analysis.

\section{Introduction}

Despite its recent decline, overall mortality in heart failure has remained very high $[1,2]$. One of the challenges of public health is to lower it. For this, the development of secondary prevention tools remains crucial. The setting up of outpatient facilities such as PRADO (Home Return Program), UTIC (Heart Failure Treatment Unit) are part of this. The biomarker research prognosis for overall mortality has been the focus of several studies. But their interest was mainly in leaving hospitalization [3]. What about patients followed in outpatient? Which markers to choose, which ones are more powerful? Their predictive value would make it possible to establish good prevention tools.

The following study simultaneously collected the overall mortality and the various markers prognostic cardiovascular [4-8] of a collective followed outpatient. From this compendium, the biomarkers most strongly associated with one-year mortality were determined and whether these biomarkers interacted with each other.

\section{Material and methods}

This is a cross-sectional case-cohort study. The data were collected from the entire population followed in UTIC of the Public Hospital of Gonesse during the period from January 2014 to April 2019.

Patients followed at the Gonesse UTIC were patients recruited during a hospitalization in Gonesse for systolic function heart failure in the acute phase.

The Gonesse Hospital is one of the main centers of the northeastern Parisian suburbs and covers a population of 300,000 people with a high rate of migrant population and low social class.
This is a group of 99 patients, of which 23 patients were excluded for various reasons such as data collected more than one year before the patient's death, loss of sight, pregnancy, renunciation.

Deceased patients were selected for cardiovascular prognostic biomarkers, such as Pro BNP (Brain Natriuretic Peptide), LVEF (left ventricular ejection fraction), Age, Na (sodium), NYHA dyspnea degree I-IV (New York Heart Association). Creatinine clearance [4-9].

These were taken in the year preceding the death during their outpatient follow-up. This period ranges from 10 months to 1 month before death. Of the 11 deaths 10 had their data collected in the 6 months preceding the death of which 4 between 6 and 4 months.

Regarding the rest of the group, the data come from their last consultation in the last 12 months (until April 2019).

The associative measure between the mortality and the selected markers was done by calculating the Odd Ratio. For this calculation, the markers are divided into 2 categories distributed around a threshold established between the difference in means obtained in the two populations (deaths and live) (Table 1).

To determine the significance of the associative measures, the confidence interval and the $\mathrm{P}$ value were calculated. The latter by

*Correspondence to: Jimmy Duc, Hopital de Gonesse, 2 bvd 19 mars 1962, 9550 Gonesse, France, Tel: 0627890414; E-mail: jimmyduc@hotmail.com

Key words: MESH, biomarqueurs, mortalité, Nt Pro BNP, pronostic, cardiovasculaire

Received: May 20, 2020; Accepted: June 01, 2020; Published: June 05, 2020 
performing a $\mathrm{T}$ test. The marker with the highest Odd Ratio was considered the main biomarker. The others selected according to were considered as co-variables. In order to check the presence of possible confounding factors, the associative measurement between the main biomarker and the one-year mortality was adjusted to the other covariables by stratification method and confirmed by multivariate analysis.

Through the homogeneity method, the presence of possible interaction between the main variable and the co-variable has been analyzed.

\section{Results}

86) $(\mathrm{p}<0.05)$

One-year mortality with a BNP Pro $>2500$ ng / 1, OR 19 (CI 4.13-

One-year mortality associated with an age $>75$ years, OR 5 (1.3-19) $(\mathrm{p}<0.05)$

One-year mortality associated with clearance $<50 \mathrm{ml} / \mathrm{min}$, OR 4 $(1.04-15)(\mathrm{p}<0.05)$

One-year mortality associated with LVEF $<40 \%$, OR 1.6 (0.4-5.8) $(\mathrm{p}>0.05)$

One-year mortality associated with a BNP Pro $>2500$ adjusted to an age $>75$ years, OR $56(4.59-682)(\mathrm{p}<0.05)$

One-year mortality associated with Pro $\mathrm{BNP}>2500$ adjusted to clearance $<50 \mathrm{ml} / \mathrm{min}$, OR $33(3.86-279)(\mathrm{p}<0.05)$

\section{Discussion}

The difference in the means of each biomarker obtained between their respective groups (deceased patients, live patients) made it possible to make a first sort (Table 1). Biomarkers: sodium and gender were not retained. The first did not show a significant difference between the two groups. Next, the male / female proportion in our sample with a rate of 5: 1 is not representative of the data in the population of heart failure [10], which is a source of bias.

The degree of dyspnea NYHA is not retained either, indeed its definition is not specific for heart failure (COPD, deconditioning) in the elderly population [9].
Of the biomarkers retained, Pro-BNP showed the greatest difference in distribution between the two groups. His association with one-year mortality was significant and high. It was selected as the main variable associated with mortality. This result remains comparable to what is found in the literature [11].

The co-variable age and clearance of creatinine also showed a positive and significant association with one-year mortality. In contrast, the association between LVEF and mortality was not significant and was not selected (Table 2).

There has been a clear increase in the association between Pro BNP and age-adjusted mortality, a strong difference suggesting the presence of a confounding factor. Strata analysis did not show a significant association between mortality and Pro BNP in the population under 75 years of age (Table 3 ). This did not allow for a thorough analysis.

The association between Pro BNP and one-year mortality was also significantly increased after adjusting for clearance. Comparing this result with the literature data, this association seems overestimated $[12,13]$. The marked difference between the two layers of clearance, suggested the presence of a confusing effect. However, the effect of the reduced size of the sample also favored this difference. This assumption is supported by the width of the confidence interval.

Nevertheless, the participation of a modifying effect in the difference between the two layers of clearance was certain (Table 4). Moreover, by deepening the analysis, after homogeneity method, we observed a positive interaction between the variable Pro BNP and its co-variable Clearance of creatinine. This interaction is explained by the development at this stage of a cardio-renal syndrome [14].

In addition to the size of our sample, the presence of a selection bias could alter the validity of our study. This was due to the high rate of exclusion of the group (23 patients out of 99 or 23\%) and the disproportion between men and women. This disproportion can be attributed in part to the recruiter [12] but also to the patient for various reasons such as psychosocial (guilt compared to relatives, selfesteem).

Table 1. Distribution in average value of risk markers in the population studied, death versus live group and percentage difference

\begin{tabular}{|c|c|c|c|}
\hline Cardiovascular risk markers & Dead $(n=11)$ & Alive $(n=65)$ & Difference (percentage) \\
\hline Pro BNP (ng/l) & 8935 & 1366 & Decrease $(85 \%)$ \\
\hline Age (years) & 77 & 67 & Decrease $(13 \%)$ \\
\hline Clearance creatinine $(\mathrm{ml} / \mathrm{min})$ & 45 & 66 & Increase $(32 \%)$ \\
\hline $\mathrm{EF}^{*}($ percentage $)$ & 37 & 46 & Decrease $(20 \%)$ \\
\hline NYHA**II-III (proportion) & 45 & 100 & Increase $(110 \%)$ \\
\hline NYHA III-IV & 54 & 0 & Decrease $(100 \%)$ \\
\hline $\mathrm{Na} * * *(\mathrm{mmol} / \mathrm{l})$ & 137 & 139 & Unchanged \\
\hline Men (proportion) & 81 & 74 & Decrease $(8 \%)$ \\
\hline
\end{tabular}

* ejection fraction of the left ventricle as a percentage

** New York Heart Association classification according to degrees of dyspnea

$* * *$ Sodium

Table 2. Correlation between cardiovascular risk markers and mortality

\begin{tabular}{|c|c|c|c|c|}
\hline Cardiovascular risk markers & Dead (n=11) & Alive (n=65) & $\begin{array}{c}\text { Odd ratio } \\
\text { (95\% value }\end{array}$ & $19(4.13-86)$ \\
\hline Pro BNP $>2500$ No (\%) & $8(72 \%)$ & $8(12 \%)$ & $5(1.3-1.9)$ \\
\hline Age $>75$ years & $7(63 \%)$ & $17(26 \%)$ & 40.05 \\
\hline Clearance $<50 \mathrm{ml} / \mathrm{min}$ & $7(63 \%)$ & $19(29 \%)$ & $<0.05$ \\
\hline $\mathrm{EF}<40 \%$ & $5(45 \%)$ & $22(34 \%)$ & $<0.05$ & $1.6(0.4-5.8)$ \\
\hline
\end{tabular}


Table 3. Correlation between ProBNP rate and mortality adjusted to age

\begin{tabular}{|c|c|c|c|c|c|}
\hline \multirow{2}{*}{ ProBNP, ng/l } & \multicolumn{3}{|c|}{ Age $>75$ years } & \multicolumn{2}{|c|}{ Age $<75 y e a r s$} \\
\cline { 2 - 5 } & $\begin{array}{c}\text { Group A } \\
(\mathrm{N}=9)\end{array}$ & $\begin{array}{c}\text { Odd ratio } \\
(95 \% \mathrm{CI})\end{array}$ & P value & $\begin{array}{c}\text { Group B } \\
(\mathrm{n}=9)\end{array}$ \\
\hline$>2500$ & $7(77 \%)$ & $56(4.59-682)$ & $<0.05$ & $1(11 \%)$ & $2.4(0.07-4.9)$ \\
\hline
\end{tabular}

*mortality rate

Table 4. Correlation between ProBNP rate and mortality adjusted to clearance

\begin{tabular}{|c|c|c|c|c|c|}
\hline \multirow{2}{*}{ ProBNP, ng/l } & \multicolumn{3}{|c|}{ Clearance $<\mathbf{5 0 ~ m l / m i n}$} & \multicolumn{2}{|c|}{ Clearance $>\mathbf{5 0}$ ml/min } \\
\cline { 2 - 5 } & $\begin{array}{c}\text { Group A } \\
(\mathrm{N}=9)\end{array}$ & $\begin{array}{c}\text { Odd ratio } \\
(95 \% \mathrm{CI})\end{array}$ & P value & $\begin{array}{c}\text { GroupeB } \\
(\mathrm{n}=9)\end{array}$ & $\begin{array}{c}\text { Odd ratio } \\
(95 \% \mathrm{CI})\end{array}$ \\
\hline$>2500$ & $6(66 \%)^{*}$ & $33(3.86-279)$ & $<0.05$ & $3(33 \%)^{*}$ & $20(1-402)$ \\
\hline
\end{tabular}

*mortality rate

\section{Conclusion}

Despite the relatively small size of this sample, the strong association between our major biomarkers and mortality, particularly the BNP Pro, was comparable to the results of previous post-discharge studies [11].

Thus, these results collected in ambulatory patients, could pave the way for further prospective studies. The goal is to develop a real secondary prevention tool for this population.

\section{References}

1. Dickstein K (2008) ESC CHF Guidelines. Eur Heart J 29: 2388-2442.

2. Bleumink GS (2006) Prevalence, incidence and lifetime risk of atrial fibrillation: the Rotterdam study. Eur Heart J 25: 1614-1619. [Crossref]

3. Viagbo K (2020) Screening and diagnosis of chronic heart failure in subjects aged 75 and over Toulouse, Toulouse III-Paul Sabatier.

4. Levine S, Sachs G, Jin L, Meltzer D (2007) Prognostic model for 1-year mortality in older adults after hospital discharge. Am J Med 120: 455-460. [Crossref]

5. Adams K, Dunlap S, Sueta C, Clarke S, Patterson J, et al. (1996) Relation between gender, etiology and survival in patients with symptomatic heart failure. $\mathrm{J} \mathrm{Am} \mathrm{Coll}$ Cardiol 28: 1781-1788. [Crossref]

6. O'Connor C, Whellan D, Wojdyla D, Leifer E, Clare R, et al. (2012) Factors related to morbidity and mortality in patients with chronic heart failure with systolic dysfunction: the HF-ACTION predictive risk score model. Circ Heart Fail 5: 63-71. [Crossref]
7. Masson S, Latini R, Anand I, Vago T, Angelici L, et al. (2006) Direct comparison of B-type natriuretic peptide (BNP) and amino-terminal proBNP in a large population of patients with chronic and symptomatic heart failure: the Valsartan Heart Failure (ValHeFT) data. Clin Chem 52: 1528-1538. [Crossref]

8. Dries D, Exner D, Domanski M, Greenberg B, Stevenson L (2000) The prognostic implications of renal insufficiency in asymptomatic and symptomatic patients with left ventricular systolic dysfunction. J Am Coll Cardiol 35: 681-689. [Crossref]

9. Gillespie N (2005) The diagnosis and management of chronic heart failure in the older patient. Br Med Bull 75: 49-62. [Crossref]

10. W Kannel, Albert J Belanger (1991) Epidemiology of Heart Failure. Am Heart J 121: 951-57. [Crossref]

11. Reny JL, Millot O, Vanderecamer T, Vergnes C, Barazer I, et al. (2007) NT-proBNP levels at admission, age and renal failure predict mortality in elderly patients hospitalized for acute dyspnea. The internal medicine journal 2: 21-30.

12. Alabas O, Gale C, Hall M, Rutherford M, Szummer K, et al. (2017) Sex differences in treatments, relative survival, and excess mortality following acute myocardial infarction: National cohort study using the SWEDEHEART registry. $J$ Am Heart Assoc 6: e007123 [Crossref]

13. Magri P, Rao M, Cangianiello S (1998) Early impairment of renal hemodynamic reserve in cardiac insufficiency. AHA Journals 1: 1-10. [Crossref]

14. Claudio R, Haapio M, House A, Anavekar N, Bellomo R (2008) Cardiorenal syndrome. J Am Coll Cardiol 4: 23-30.

Copyright: (C2020 Duc J. This is an open-access article distributed under the terms of the Creative Commons Attribution License, which permits unrestricted use, distribution, and reproduction in any medium, provided the original author and source are credited. 